\title{
Mapping local singularities using magnetic data to investigate the volcanic rocks of the Qikou depression, Dagang oilfield, eastern China
}

\author{
G. Chen ${ }^{1,2}$, Q. Cheng ${ }^{1,2,3}$, T. Liu ${ }^{4}$, and Y. Yang ${ }^{4}$ \\ ${ }^{1}$ State Key Laboratory of Geological Processes and Mineral Resources, China University of Geosciences, \\ Wuhan, 430074, China \\ ${ }^{2}$ Faculty of Earth Resources, China University of Geosciences, Wuhan, 430074, China \\ ${ }^{3}$ Department of Earth and Space Science, Department of Geography, York University, Toronto, M3JIP3, Canada \\ ${ }^{4}$ Institute of Geophysics and Geomatics, China University of Geosciences, Wuhan, 430074, China \\ Correspondence to: G. Chen (chengxhg@163.com) and Q. Cheng (qiuming@yorku.ca)
}

Received: 17 January 2013 - Revised: 19 May 2013 - Accepted: 23 May 2013 - Published: 12 July 2013

\begin{abstract}
The spatial structural characteristics of geological anomaly, including singularity and self-similarity, can be analysed using fractal or multifractal modelling. Here we apply the multifractal methods to potential fields to demonstrate that singularities can characterise geological bodies, including rock density and magnetic susceptibility. In addition to enhancing weak gravity and magnetic anomalies with respect to either strong or weak background levels, the local singularity index $(\alpha \approx 2)$ can be used to delineate the edges of geological bodies. Two models were established to evaluate the effectiveness of mapping singularities for extracting weak anomalies and delineating edges of buried geological bodies. The Qikou depression of the Dagang oilfield in eastern China has been chosen as a study area for demonstrating the extraction of weak anomalies of volcanic rocks, using the singularity mapping technique to analyse complex magnetic anomalies caused by complex geological background. The results have shown that the singularities of magnetic data mapped in the paper are associated with buried volcanic rocks, which have been verified by both drilling and seismic survey, and the $\mathrm{S}-\mathrm{N}$ and $\mathrm{E}-\mathrm{W}$ faults in the region. The targets delineated for deeply seated faults and volcanic rocks in the Qikou depression should be further investigated for the potential application in undiscovered oil and gas reservoirs exploration.
\end{abstract}

\section{Introduction}

Since the beginning of the 20th century, volcanic reservoirs have been found globally in large numbers; prominent examples include the Dineh-bi-Keyah syenite reservoirs in Arizona in the United States, the Samgori tuff reservoirs in Georgia, and the Mulradkhanly andesite and basalt reservoirs in Azerbaijan (Zhang and Wu, 1994). Consequently, oil and gas exploration companies have begun to pay more attention to volcanic reservoirs worldwide. In general, volcanic rocks exhibit higher magnetic susceptibility than sedimentary rocks and this can result in apparent magnetic anomalies when there is shallow burial. Therefore, the spatial distribution of volcanic rocks can be delineated according to magnetic anomaly maps (Mickus and Durrani, 1996; Wu et al., 2010; Xu et al., 2011; Yang et al., 2012). However, the volcanic reservoirs of China are typically buried more deeply than those elsewhere in the world (Yang et al., 2006) and, consequently, produce very weak magnetic anomalies. For example, the Zhangjuhe volcanic reservoir in the Qikou depression in eastern China has a burial depth of $3100 \mathrm{~m}$ and is less than $10 \mathrm{~m}$ thick. Thus, the identification of weak geophysical anomalies requires the adoption of more sensitive techniques, especially in regions with high magnetic background levels.

In recent decades, nonlinear science has been revitalised owing to the invention of the fractal and multifractal concepts (Mandelbrot, 1967, 1972; Benzi et al., 1984). According to nonlinear theory, the phenomenon in which an anomalous 
amount of energy (material) is released (accumulated) within a narrow spatial-temporal interval can result in a singularity (Cheng, 2006). Singularities form the basis of a variety of nonlinear and complex geological processes caused by unusual geological events and can be expressed as fractal or multifractal distributions. The local singularity index was used initially to quantify spatial singularities. Cheng (1997) first proposed an equation to define the value of the local singularity index and subsequently published a series of papers describing the application of singularity theory to the prediction of tin and copper mineral deposits in the Gejiu district, Yunnan province, China (Cheng, 2007, 2010, 2006). Recently, Cheng (2012) confirmed systematically that the singularity mapping technique is effective for use in the recognition of weak anomalies caused by buried minerals. Many scholars have further expanded the application of the singularity mapping technique (Chen et al., 2007; Wang et al., 2013; Wang et al., 2012; Xie et al., 2007; Zuo et al., 2009).

The concept of fractals has also been applied successfully in geophysical field studies, including earthquakes (Hirabayashi et al., 1992; Dimitriu et al., 2000; Hirata and Imoto, 1991; Godano et al., 1996; Turcotte, 1992), rain and clouds (Schertzer and Lovejoy, 1987), crustal magnetization and rock density (Lovejoy et al., 2008, 2001). Additionally, Mostafa $(2008,2009)$ studied the characteristics of gravity and magnetic anomalies produced by self-similar fractal forward models. Cheng (2001) considered that geo-anomalies including geochemical and geophysical data exhibit properties of spatial or statistical self-similarity. Related research has resulted in major breakthroughs in the application of multifractal analysis and singularity theory to mineral identification (Cheng and Zhao, 2011), extraction of geochemical anomalies (Agterberg, 2012; Zuo et al., 2013; Zuo and Cheng, 2008), and processing of remote sensing data (Cheng and $\mathrm{Li}, 2002$ ). However, insufficient research has been conducted regarding the application of singularity theory in the geophysical domain (Wang et al., 2013), particularly with regard to the properties of the local singularity index for the potential field data (gravity and magnetic anomalies). Here, we aim to introduce a method for mapping local singularities, based on the multifractal method and potential field theory, into the domain of gravity and magnetic exploration, and discuss the properties of singularities. We then apply our method to a case study from the Qikou depression district, eastern China, to verify the effectiveness of our method of delineating the distribution of volcanic rocks.

\section{Methods}

\subsection{Multifractal modelling and singularity analysis in geosciences}

The singularity phenomenon occurs commonly in the natural sciences, such as in relation to volcanic eruptions, earth- quakes, landslides, and mineralization (Cheng, 2006). Singularity is a generic property of nonlinear natural processes that often generates end products depicting fractality or multifractality (Cheng, 2012; Cheng and Agterberg, 2009). Zhao (1988) considers geo-anomalies related to mineral sources to be a result of nonlinear dynamical processes. Similarly, the low- or high-density and susceptibility mass can lead to singularities of gravity and magnetic anomalies. Strictly speaking, traditional Fourier transform and wavelet analysis are unsuitable for processing singularity data because of their nonlinear and nonstationary properties (Chen et al., 2011, 2007). The latest research into nonlinear and complexity theories suggest that singularities are typically scale invariant, following fractal or multifractal distributions, and the values of singularity can be estimated for every location of geo-anomalies and used as a quantity for characterizing the anomalies caused by buried sources (Cheng, 2006, 2012; Cheng and Zhao, 2011).

From a fractal or multifractal point of view, a measure is denoted as $\mu\left(B_{Q}(\varepsilon)\right)$ with the size $\varepsilon$ located at $Q$, the object's fractal properties can be characterised by studying how $\mu\left(B_{Q}(\varepsilon)\right)$ varies with decreasing $\varepsilon . \mu\left(B_{Q}(\varepsilon)\right)$ follows a power-law relationship with $\varepsilon: \mu\left(B_{Q}(\varepsilon)\right) \propto \varepsilon^{\alpha(Q)}$, where $\alpha(Q)$ is known as the coarse Hölder exponent, also termed the local singularity index in this paper. Cheng (1997) proposed the following ratio of the logarithmic transformation of $\mu$ and $\varepsilon$ to estimate the value of the singularity index.

$\alpha_{Q}=\log \left(\mu\left(\varepsilon_{1}\right) / \mu\left(\varepsilon_{2}\right)\right) / \log \left(\varepsilon_{1} / \varepsilon_{2}\right)$,

where $\mu\left(\varepsilon_{1}\right)$ and $\mu\left(\varepsilon_{2}\right)$ are measures corresponding to $\varepsilon_{1}$ and $\varepsilon_{2}$, respectively.

\subsection{Singularity analysis of potential field data}

A power-law relationship is evident in the potential field, such that the intensity of gravity or magnetic anomaly undergoes a characteristic decay with distance. A reduced function that presents this relationship can be expressed as follows:

$f(x, y, z)=\frac{F}{r^{N}}$,

where $r=\sqrt{\left(x^{2}+y^{2}+z^{2}\right)}$ is the distance from the observation to the geological body and $F$ is an amplitude factor. $N$ is referred to as the structure index by Thompson (1982), and is associated with the nature of the source geometry. The value of $N$ is independent of scale $r$. For a magnetic sphere, $N=3$; conversely, $N=2$ for a magnetic horizontal cylinder and $0 \leq N \leq 3$ for other types of geological bodies. Equation (2) indicates that the potential field exhibits 3-D spatial selfsimilarity; therefore, the 2-D gravity and magnetic anomalies observed at height $(h)$ above the horizontal plane will also exhibit self-similarity in the area surrounding the geological body. Thus, it is possible to obtain the singularity distribution of gravity or magnetic anomaly by applying the 2-D local singularity index estimation method (Cheng, 2006). 
For a 2-D gravity or magnetic anomaly, a small box $B_{Q}(\varepsilon)$ with size $\varepsilon$ centred at $Q(x, y)$ is assumed, and the total amount of the potential field data in this area is denoted by $\mu\left(B_{Q}(\varepsilon)\right)$. From a generalised multifractal point of view, the singularity phenomenon can be described as the following power-law relationship:

$\mu\left(B_{Q}(\varepsilon)\right)=c \varepsilon^{\alpha(x, y)}$,

where the exponent $\alpha(x, y)$ is the local singularity index, $c$ is a constant, and the concentration $\rho\left(B_{Q}(\varepsilon)\right)$ of the potential field data can be expressed as follows:

$\rho\left(B_{Q}(\varepsilon)\right)=\frac{\mu\left(B_{Q}(\varepsilon)\right)}{\varepsilon^{2}}=c \varepsilon^{\alpha(x, y)-2}$.

After logarithmic transformation, Eq. (4) can be written as

$\log \left(\rho\left(B_{Q}(\varepsilon)\right)\right)=(\alpha(x, y)-2) \log (\varepsilon)+\log (c)$.

Equation (5) indicates a linear relationship between $\log (\rho(\varepsilon))$ and $\log (\varepsilon)$, and the slope of this linear relationship can be calculated through least-squares fitting.

We applied a window-based method to estimate the local singularity from gravity or magnetic anomaly data; this method can be summarised as follows. (1) Given a sampling point on the map, define a set of windows (square, circular, rectangular, or elliptical) with variable window sizes $\varepsilon_{\min }=\varepsilon_{1}<\varepsilon_{2}<\ldots<\varepsilon_{n}=\varepsilon_{\max }$. (2) Ensure that the gravity or magnetic data are greater than zero and calculate the concentration $\rho$ of the potential field for each window. (3) According to Eq. (5), the $(\alpha-2)$ value of the sampling point can be calculated based on the slope of the straight line using the least-squares method. (4) Similar treatment with a sliding window for all locations on the map allows the creation of a singularity distribution map. Additionally, different ranges of $\left[\varepsilon_{\min }, \varepsilon_{\max }\right]$ may be used to ensure distinct power law functions, and these may yield singularities at different scales (Cheng, 2006). For example, a small-scale singularity may reflect local anomalies associated with mineralization, whereas a large-scale singularity may represent regional background variability.

Figure 1a and $\mathrm{b}$ illustrate the positive gravity anomaly of a high-density contrast $\left(\Delta \sigma=0.6 \mathrm{~g} \mathrm{~cm}^{-3}\right)$ sphere and negative anomaly of a low-density contrast $\left(\Delta \sigma=-0.6 \mathrm{~g} \mathrm{~cm}^{-3}\right)$ sphere, respectively. We used the window-based method described above to estimate the local singularity index of the gravity anomalies produced by each sphere. Two log-log (base 10) plots (Fig. 1c and d) illustrate the relationship between the concentration values $\rho$ of gravity anomalies and the box size $\varepsilon$, for the high- and low-density spheres, respectively; these spheres have singularity index values of $\alpha_{1}=1.9616$ and $\alpha_{2}=2.04$, respectively.

\subsection{Properties of singularity index $\alpha$}

In general, the local singularity index can be divided into three cases: if $\alpha<2, \rho$ is a decreasing function of $\varepsilon$ (Fig. 1c), which implies positive singularity over a small area centred around the given location; if $\alpha>2, \rho$ is an increasing function of $\varepsilon$ (Fig. 1d), which implies negative singularity; $\rho$ is a constant only if $\alpha=2$, regardless of $\varepsilon$. For 2-D gravity anomalies or RTP (reduction to the pole) magnetic anomalies, the further $\alpha$ value deviates from the Euclidean space with dimension $E=2$, the stronger the singularity. As is shown in Fig. 1, "singular" locations where $\alpha<2$ generally indicate abnormal high-density or susceptibility mass; those where $\alpha>2$ indicate low-density or susceptibility mass; and those where $\alpha=2$ generally indicate the regional background field. The local singularity index can be used instead of the potential field value to characterise gravity and magnetic anomalies near the earth's surface.

Additionally, Cheng $(2008,2012)$ suggested that the power-law relationship defined by Eq. (3) could be expressed as

$\alpha=\frac{\mathrm{d} \mu(\varepsilon)}{\mathrm{d} \varepsilon} \frac{\varepsilon}{\mu(\varepsilon)}$,

where the singularity transformation involves the derivative of the measure $\mu$. In fact, the value of singularity index $\alpha$ measures the change rate of $\mu$ with increasing $\varepsilon$, and it is similar to the horizontal and vertical directional derivative of the potential field. Therefore, according to the physical meaning of the derivative, the singularity index acts as a high-pass filter transformation of $\mu$ and can solve two main issues as follows. First, it can characterise the differences between local anomalies and regional field, and remove the effects of a strong background field to enhance weak gravity and magnetic anomalies. In such cases, the gradient of local field remains large, while the regional field is close to zero. Second, the index can delineate edges of geological bodies which generally correspond to the gradient of potential field. The total amount $\mu(\varepsilon)$ of potential field data with different $\varepsilon$ remain almost constant at an inflection point on the gradient of an anomaly when we apply window-based method, because the increases and decreases of potential field offset each other around the inflection point, therefore, the value of singularity index close to two.

\section{Synthetic examples}

\subsection{Recognition of weak magnetic anomaly}

We applied our method to recognise weak magnetic anomalies in complex geologic settings. The theoretical models employed include two types of source: the regional field was generated by a quadratic trend surface (Fig. 2a) with $5 \mathrm{~m}$ sampling interval, and the local anomalies were produced by three spheres with different burial depths and radii (Fig. 2b). Table 1 presents the forward model parameters. The patterns in Figs. $2 \mathrm{c}$ and $4 \mathrm{~b}$ show that the magnetic anomalies caused by spheres become very weak after superposition of the local anomalies on the background field. 

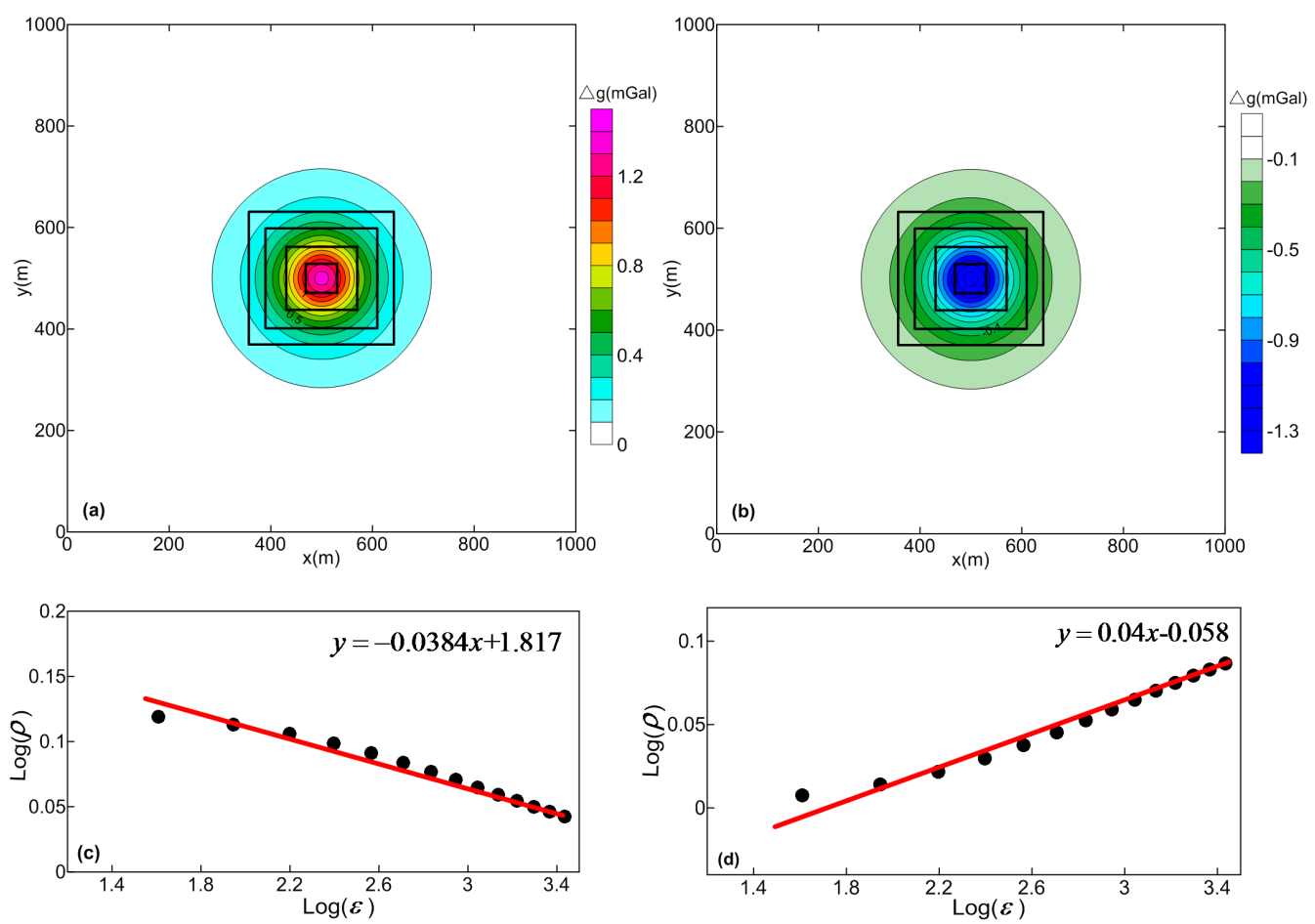

Fig. 1. The upper plots illustrate local singularity calculation of forward gravity anomalies produced by (a) high- and (b) low-density spheres. The $\log -\log$ plots illustrate the relationship between the concentration values $\rho(\varepsilon)$ and the box size $\varepsilon$, centred at the (c) high- and (d) lowdensity spheres.
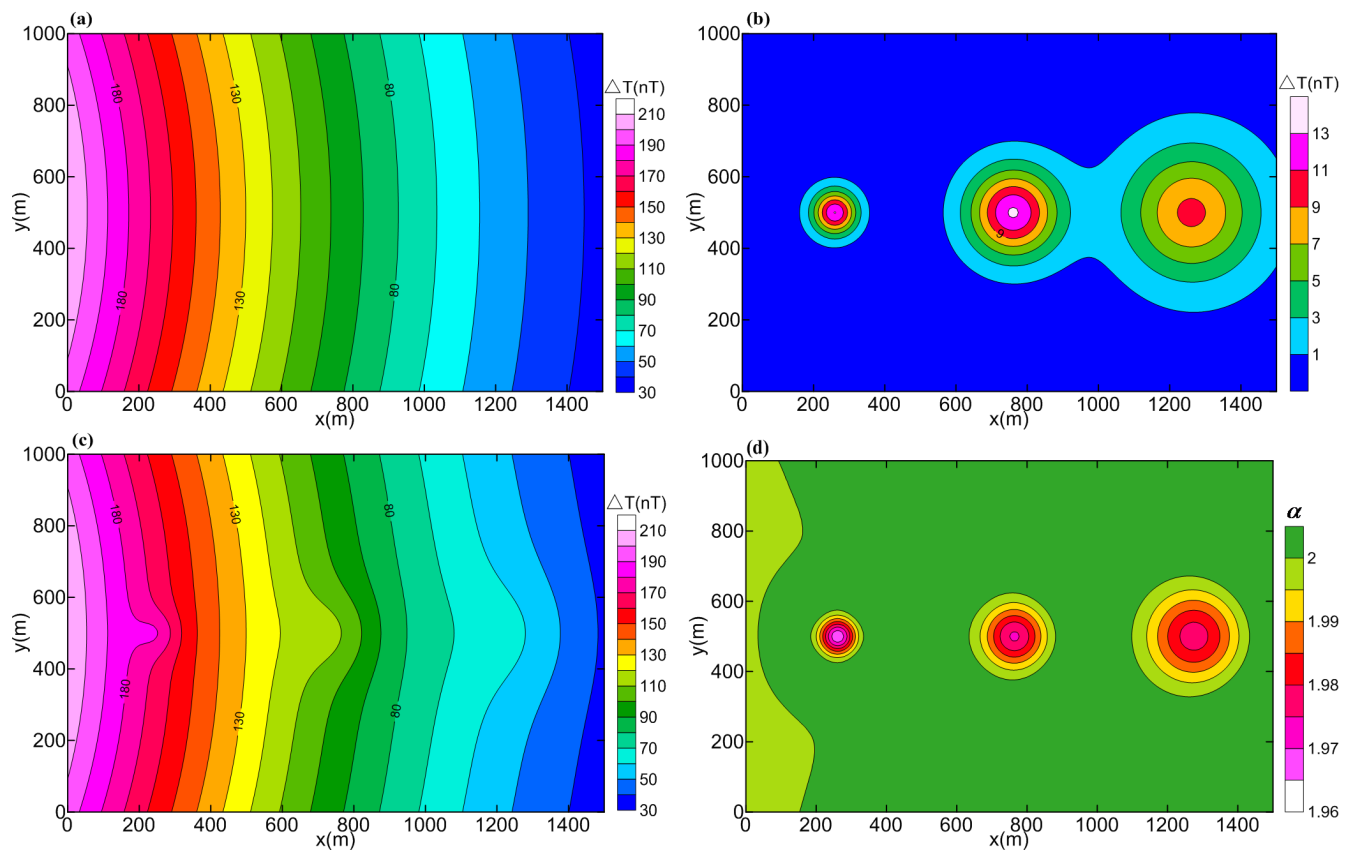

Fig. 2. Application of singularity mapping technique in theoretical magnetic anomalies: (a) a regional magnetic field generated by a quadratic trend surface; (b) local magnetic anomalies produced bythree spheres with different burial depths and radii; (c) synthetic magnetic anomalies which are the superposition of the local anomalies on the regional field; and (d) estimated singularity $\alpha$ value derived using the window-based method. 
The window-based method, which employs a variable window size $\left[\varepsilon_{\min }, \varepsilon_{\max }\right]=[10 \mathrm{~m}, 80 \mathrm{~m}]$ and sliding interval of $10 \mathrm{~m}$, was used to estimate the local singularity from the theoretical magnetic anomaly data. The log-log plots in Fig. 3a and b illustrate the relationship between $\rho(\varepsilon)$ and $\varepsilon$ in the local anomaly area (the sphere centre) and regional field area $(x=900 \mathrm{~m}, \mathrm{y}=900 \mathrm{~m})$, respectively. Figure $2 \mathrm{~d}$ illustrates the distribution of $\alpha$ value; it is clear that $\alpha \approx 2$ for the regional field area, while $\alpha<2$ in the region surrounding the three spheres (Figs. $2 \mathrm{~d}$ and $4 \mathrm{c}$ ), whose positive singularities indicate abnormal high-susceptibility mass. Thus, we have confirmed that our singularity mapping technique can extract these weak anomalies from the strong background effectively, especially for the spheres that are buried at greater depths (spheres 2 and 3; Table 1). Furthermore, the locations of maximum singularity identified the centres of the three spheres correctly (seen in Fig. 4c-d).

\subsection{Delineation of magnetic source}

We used a complexity model (illustrated in Fig. 5) to ascertain which geological information can be provided by the singularity index. Figure 5a shows the theoretical magnetic anomalies produced by four rectangular models with $0.2 \mathrm{~km}$ sampling interval; Table 2 presents the forward model parameters. We set a square window size $\left(\varepsilon_{\min }, \varepsilon_{\max }\right)=(0.2 \mathrm{~km}, 1 \mathrm{~km})$ with a $0.2 \mathrm{~km}$ sliding interval. The areas where $\alpha \approx 2$ reflect the edges of the four rectangular models very well, especially for those rectangles at greater depths (1 and 4; Fig. 5b). Areas in which $\alpha<2$ represent the locations of rectangular models. Based on these data, we were inspired to use the singularity mapping technique not only to estimate the locations and edges of gravity and magnetic source bodies, but also to delineate concealed faults, sedimentary basins, and other geological targets.

\section{Application of the singularity mapping technique to potential field data}

\subsection{Geological setting}

The Qikou main sag is located in the northern central part of the Huanghua depression of the Bohai Bay basin in eastern China (seen in Fig. 6) and is surrounded by the Saleitian uplift in the east, the Gangxian uplift in the west, the Beitang sag in the north, and the Chengnin uplift in the south (Zhou et al., 2012; Huang et al., 2012). The tectonic framework of this area can be divided into four buried hills (Tanggu, Nandagang, Beidagang, and Yangsanmu) and three sags (Qikou main sag, Qibei sag, and Qinan sag). Two sets of faults cut through the Qikou depression, including NW-SE trending faults (the North Dagang, South Dagang, Zhangjuhe, and Yangerzhuang faults) and nearly east-west trending faults (the Yangbei, Koucun, and Huanghua faults). Cenozoic volcanic rocks, such as basalts, andesites, diabases, and volcanic
Table 1. Forward model parameters.

\begin{tabular}{lcccc}
\hline $\begin{array}{l}\text { Model } \\
\text { number }\end{array}$ & Magnetization & $\begin{array}{c}\text { Magnetic } \\
\text { inclination } \\
\left(10^{-3} \mathrm{Am}^{-1}\right)\end{array}$ & $\begin{array}{c}\text { Radius } \\
(\mathrm{m})\end{array}$ & $\begin{array}{c}\text { Sphere centre } \\
\text { position }(\mathrm{x}, \mathrm{y}, \mathrm{z}) \\
(\mathrm{m})\end{array}$ \\
\hline Sphere 1 & 2000 & $90^{\circ}$ & 20 & $(260,500,100)$ \\
Sphere 2 & 2000 & $90^{\circ}$ & 40 & $(760,500,200)$ \\
Sphere 3 & 2500 & $90^{\circ}$ & 50 & $(1260,500,300)$ \\
\hline
\end{tabular}

Table 2. Theoretical model parameters.

\begin{tabular}{lccc}
\hline $\begin{array}{l}\text { Model } \\
\text { number }\end{array}$ & $\begin{array}{c}\text { Length } \times \text { width } \\
\times \text { height } \\
(\mathrm{km})\end{array}$ & $\begin{array}{c}\text { Rectangle centre } \\
\text { position }(\mathrm{x}, \mathrm{y}, \mathrm{z}) \\
(\mathrm{km})\end{array}$ & Magnetization \\
\hline 1 & $6 \times 2 \times 2$ & $6,14,2$ & $\left(10^{-3} \mathrm{Am}^{-1}\right)$ \\
2 & $1 \times 2 \times 1$ & $15,15,1$ & 1000 \\
3 & $4 \times 1 \times 1$ & $6,6,1$ & 1000 \\
4 & $2 \times 6 \times 2$ & $14,6,2$ & 1000 \\
\hline
\end{tabular}
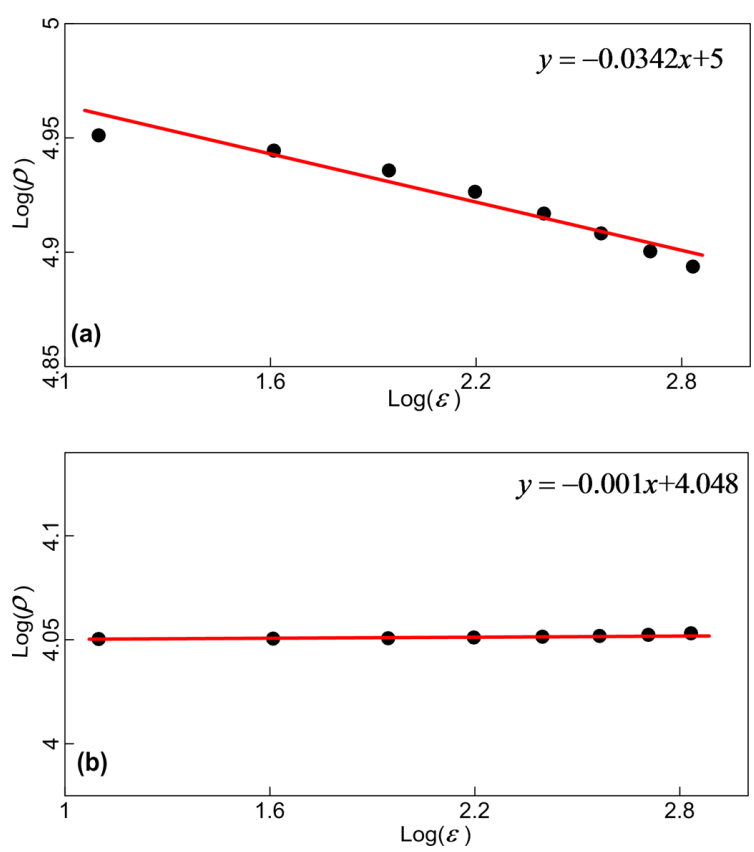

Fig. 3. (a) Log-log (base 10) plot showing the relationship between the average concentration values $\rho(\varepsilon)$ and the box size $\varepsilon$ centred at sphere 1 with coordinates $(x=260 \mathrm{~m}, \mathrm{y}=500 \mathrm{~m})$ in Fig. 2c. (b) Log-log (base 10) plot showing the relationship between the average concentration values $\rho(\varepsilon)$ and the box size $\varepsilon$ located in the regional field area with coordinates of $(x=900 \mathrm{~m}, \mathrm{y}=900 \mathrm{~m})$ in Fig. 2c. 

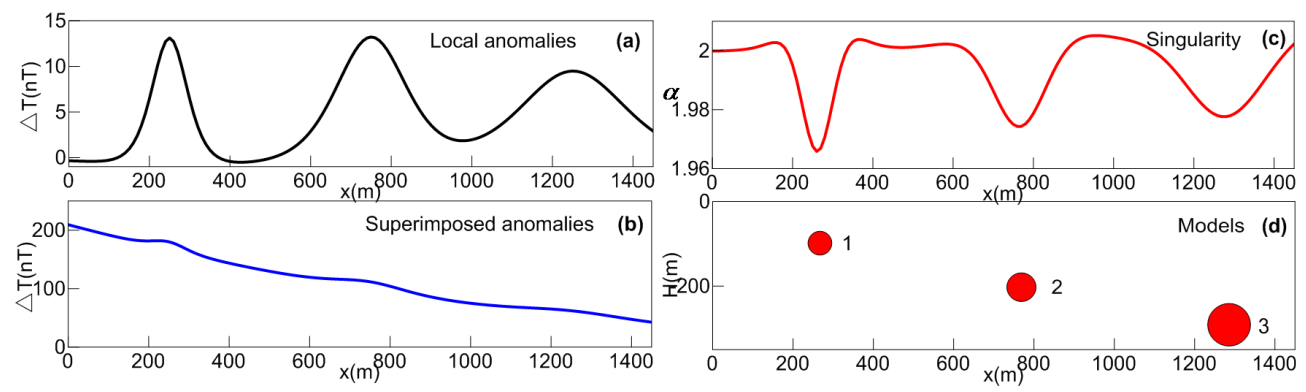

Fig. 4. Illustration showing weakly magnetic anomaly extraction using the singularity mapping technique for the profile at $\mathrm{y}=500 \mathrm{~m}$ in Fig. 2c: (a) local magnetic anomaly; (b) total magnetic anomalies which are the superposition of the local anomalies on the regional field; (c) estimated local singularity $\alpha$ value, and (d) model profile.
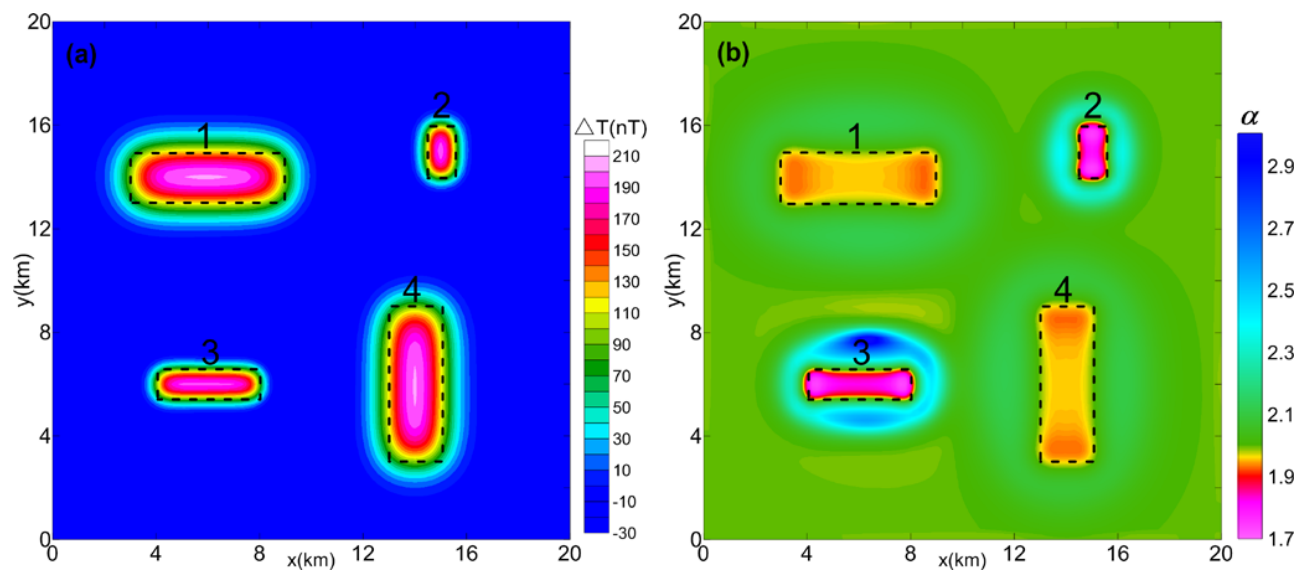

Fig. 5. Illustration showing magnetic source edge detection using the singularity mapping technique: (a) theoretical magnetic anomalies produced by four rectangular models; (b) estimated local singularity $\alpha$ value. The black dotted lines indicate the boundaries of the four rectangular bodies.

tuffs, occur extensively throughout the Qikou depression, distributed primarily in the Shahejie, Dongying, and Guantao formations; some rocks of the Minghuazhen Formation and some Mesozoic strata also occur. To date, seven volcanic reservoirs and two oilfields producing ten million tons of oil per year have been identified in the Qikou depression (Lang, 2008).

\subsection{Magnetic data and petrophysical properties}

Most volcanic rocks exhibit stronger magnetism owing to their higher ferromagnetic mineral contents. The susceptibilities of volcanic rocks vary between $200 \times 10^{-5}$ SI and $4000 \times 10^{-5}$ SI, while the susceptibilities of typical basin sediments (mudstone and sandstone) vary between $0 \times 10^{-5} \mathrm{SI}$ and $83 \times 10^{-5}$ SI. Therefore, volcanic rocks usually produce stronger magnetic anomalies than other rocks, allowing the use of aeromagnetic data in delineation of their distribution. However, drill hole data indicate that the volcanic rocks of the Qikou depression are buried at depths ranging from $1 \mathrm{~km}$ to $3.5 \mathrm{~km}$ (Yang et al., 2010).
The $1: 200000$ aeromagnetic data were acquired at a flight altitude of $90 \mathrm{~m}$ in the north-south orientation, and the distance of flight lines is $2 \mathrm{~km}$ with point spacing $60 \mathrm{~m}$. The data was gridded with $0.5 \mathrm{~km}$ grid spacing in both the north and south directions. The regional magnetic inclination and declination are $56.01^{\circ}$ and $-6.01^{\circ}$, respectively. Figure 7 illustrates the RTP aeromagnetic anomalies: no obvious relationship exists between these anomalies and volcanic rocks owing to the burial depth of the rocks. Therefore, the identification of volcanic rocks in this area from RTP aeromagnetic data becomes very difficult without extraction of anomalies. Wu et al. (2010) extracted weak magnetic anomalies in this area using the multiscale wavelet analysis method and found that local magnetic anomalies correspond more closely to the locations of wells that drilled through volcanic rocks (Fig. 8). However, some wells were still located in areas of negative anomalies, such as to the south of Qikou, to the southwest of Tangjiahe at Beidagang buried hill, and so on. 


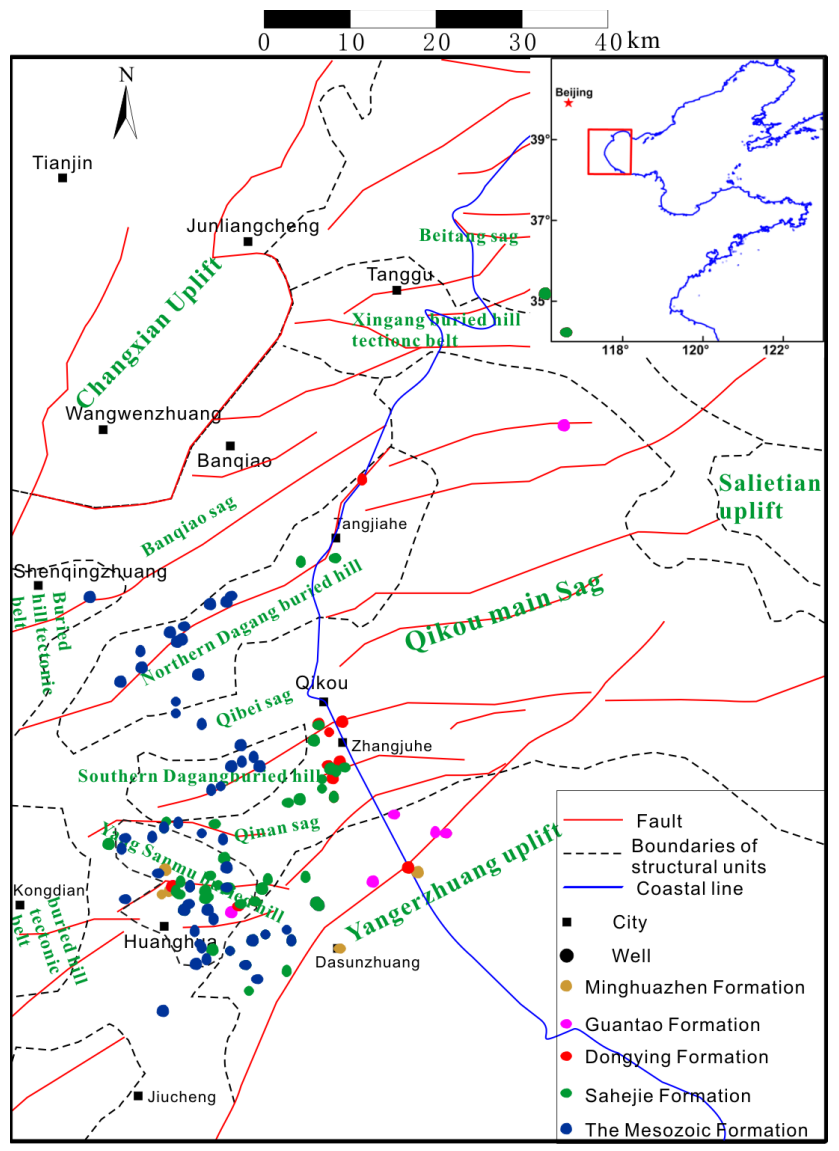

Fig. 6. Simplified geological map of the Qikou depression, eastern China. The red square in the upper right corner of the map indicates the regional location of our study area. Coloured circles represent the locations of wells that drilled through different volcanic rocks (modified from Yang et al., 2010).

\subsection{Data processing results and interpretations}

We used the local singularity mapping technique to process the RTP aeromagnetic data for the Qikou depression. We set a square window size $\left(\varepsilon_{\min }, \varepsilon_{\max }\right)=(0.5 \mathrm{~km}, 4 \mathrm{~km})$ and a sliding interval of $0.5 \mathrm{~km}$. We found a good linear relationship between $\log (\rho(\varepsilon))$ and $\log (\varepsilon)$ at point $n$ (Figs. 7 and 9), which indicates that the size of the square window is suitable. We created the singularity distribution map (Fig. 10) by applying a similar method for sliding windows at all locations on the RTP aeromagnetic map. Most of the wells that drilled through volcanic rocks were located in areas of positive singularity. Moreover, compared to the results presented in Fig. 8, there are obvious positive singularities south of Qikou and southwest of the Tangjiahe region. That is, the correspondence between local singularities and volcanic rocks is more obvious than the local anomalies extracted using the multiscale wavelet analysis method (Fig. 8). In addition, few wells are located within areas of negative singularity, likely owing to the fact that the volcanic deposits are deeply buried

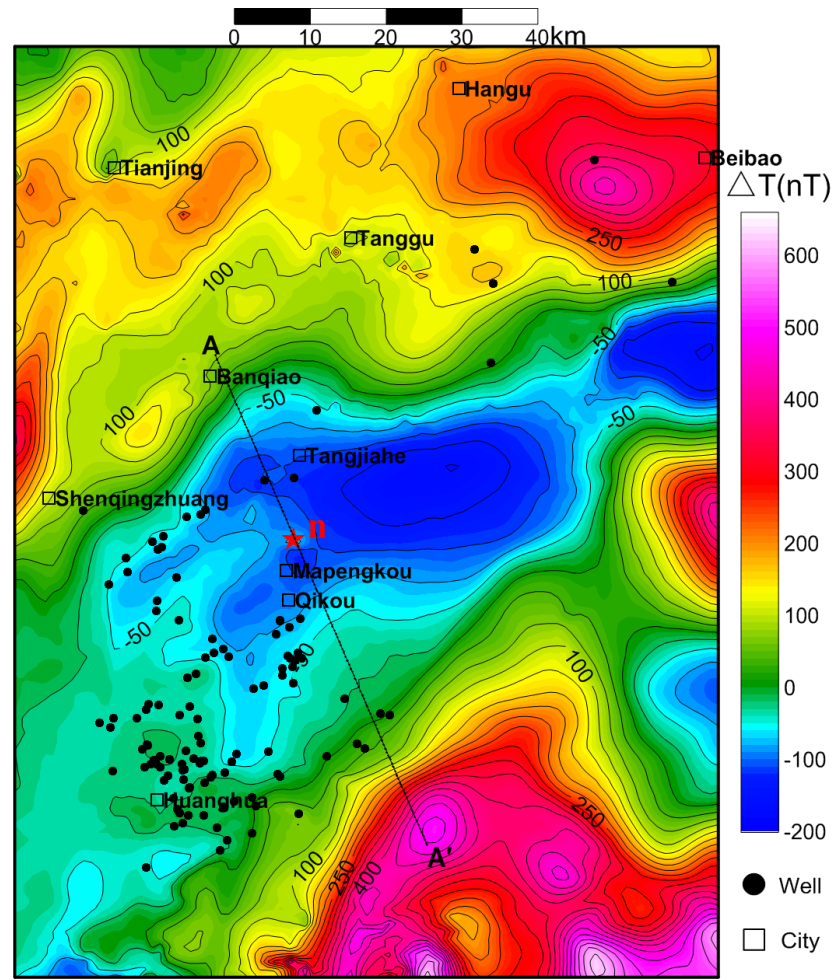

Fig. 7. The RTP magnetic anomalies of our study area; $A-A^{\prime}$ is the location of the magnetic anomaly profile in Fig. 12 and $n$ indicates the location of the plot in Fig. 9.

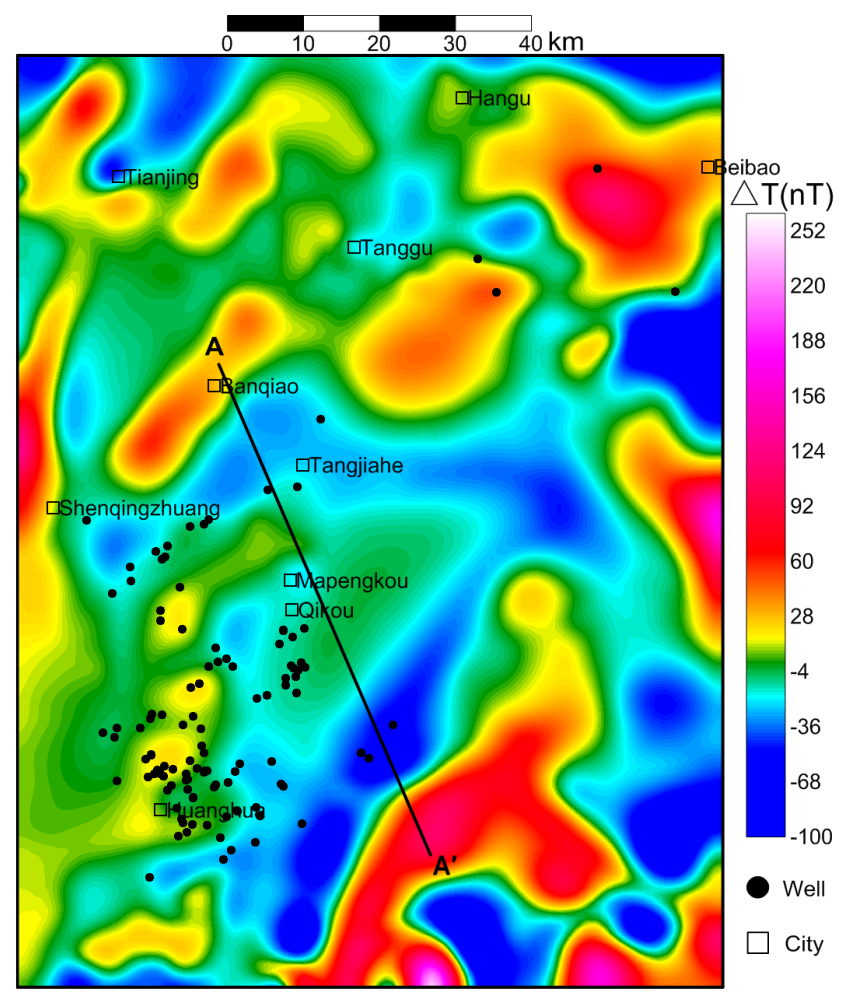

Fig. 8. Local magnetic anomalies extracted by multiscale wavelet analysis, comprising primarily second and third wavelet details after Wu et al. (2010). 


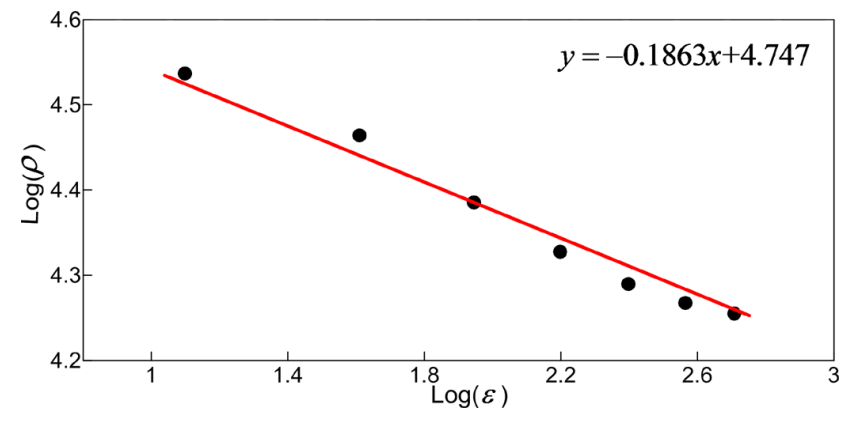

Fig. 9. $\log -\log$ (base 10) plot showing the relationship between the concentration values $\rho(\varepsilon)$ and the box size $\varepsilon$ centred at point $n$ in Fig. 7.

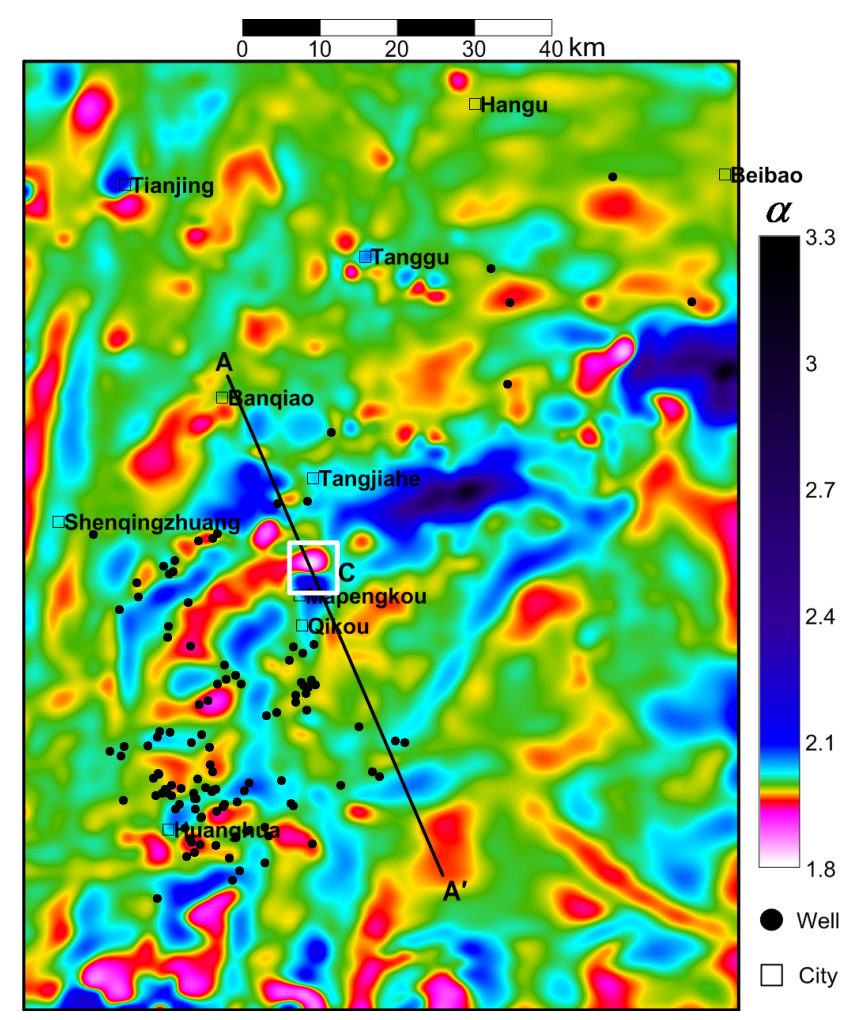

Fig. 10. Distribution of singularity indices in the aeromagnetic data; the white box indicates the seismic zone illustrated in Fig. 11.

and small in scale or due to the low susceptibility induced by hydrothermal alteration.

In our study area, positive singularities are produced directly by high-susceptibility volcanic rocks in support of using the magnetic singularity map to identify the distribution of volcanic rocks. For example, we found sharp positive singularities to exist in the Mapengkou area (Figs. 10 and 12b), where neither the RTP magnetic anomaly nor its wavelet details are apparent (Fig. 12a). However, information from a seismic profile B-B' (Fig. 12c) and seismic time slice (Fig. 11) in the Mapengkou area confirms the presence of a

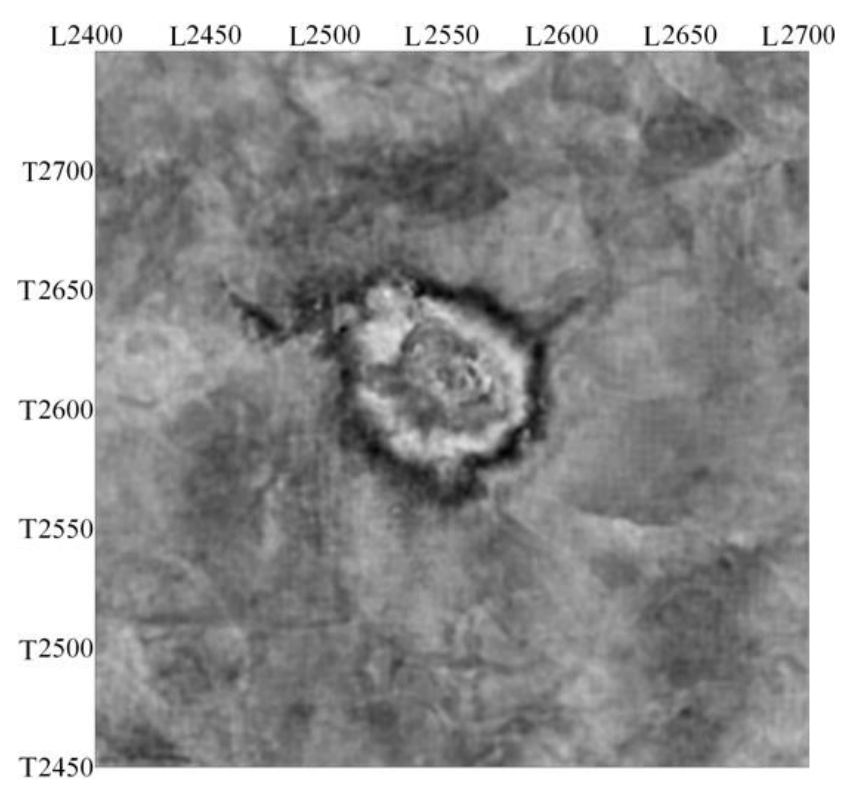

Fig. 11. Seismic time slice at $716 \mathrm{~ms}$ in Mapengkou region.

typical volcanic body sandwiched in between sediments with strong amplitude produced by different wave impedance.

In this section, we have defined the deep-seated faults and the distribution of volcanic rock targets (Fig. 13) in the seismic work areas of the Qikou depression based on analysis of the features of the magnetic singularities. These targets require further study, particularly in the area to the southeast of the seismic work area near the Chengnin uplift, in the area around the junction between the Beidagang buried hill and Qibei sag, and in the eastern Mapengkou district to the south of the Qikou main sag. The deep-seated fault system, especially the N-S trending faults (seen in Fig. 13), is likely the main factor controlling magma intrusion and the distribution of volcanic rocks in the Qikou depression.

\section{Conclusions}

From the self-similarity and singularity viewpoints, gravity and magnetic anomalies can be modelled by using the powerlaw relationship model. Unlike some traditional geophysical data processing methods, the singularity mapping technique provides a novel alternative for extracting weak anomalies from background according to their different fractal dimensional properties. The advantages of this method can be summarised as follows. (1) The local singularity indices can be used instead of the true gravity and magnetic anomalies to delineate the source distribution. (2) It can overcome the effects of strong or weak background in order to enhance weak gravity or magnetic anomalies. (3) It is not only capable of identifying the boundaries of buried sources, but can also delineate concealed faults, sedimentary basins, and other geological targets. 

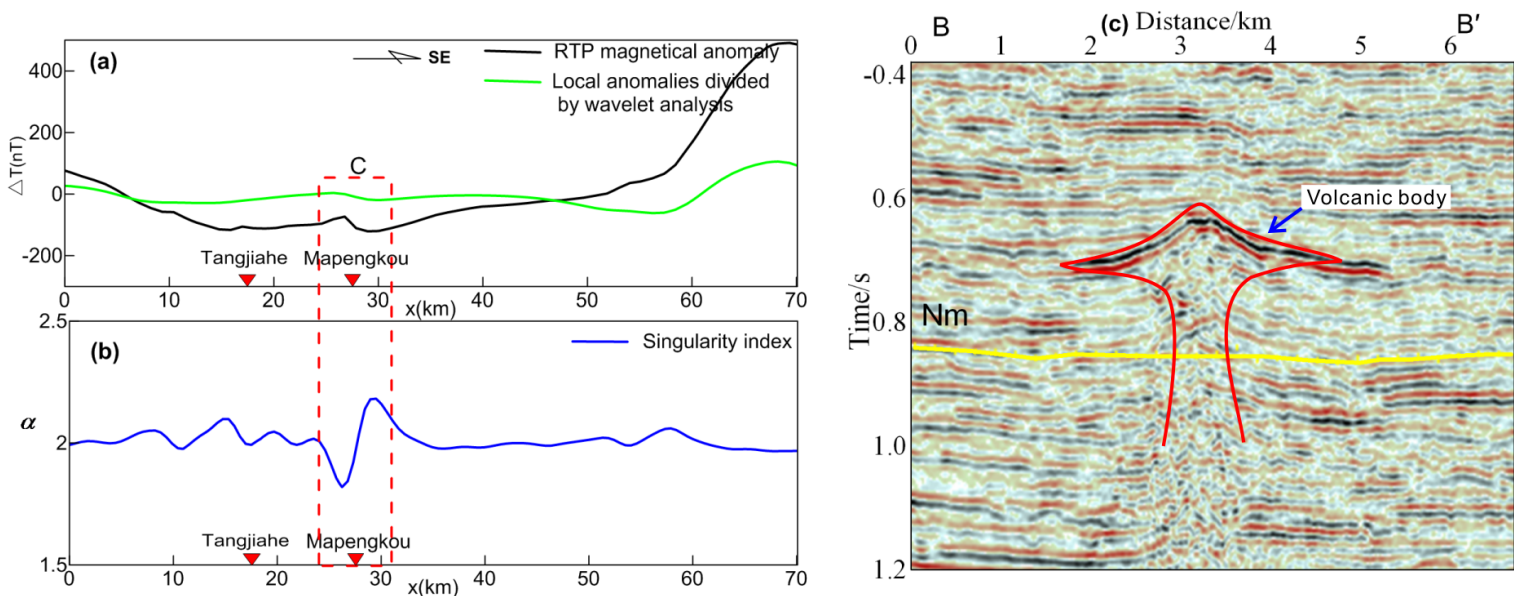

Fig. 12. Illustration of profile $A-A^{\prime}$ : (a) the black line indicates the magnetic anomalies and the green line the local anomalies detected by multiscale wavelet analysis; (b) the blue line represents the singularity indices; and (c) the seismic profile B-B', located in the red dotted box at Mapengkou, the yellow line represents the strata of the Minghuazhen formation.

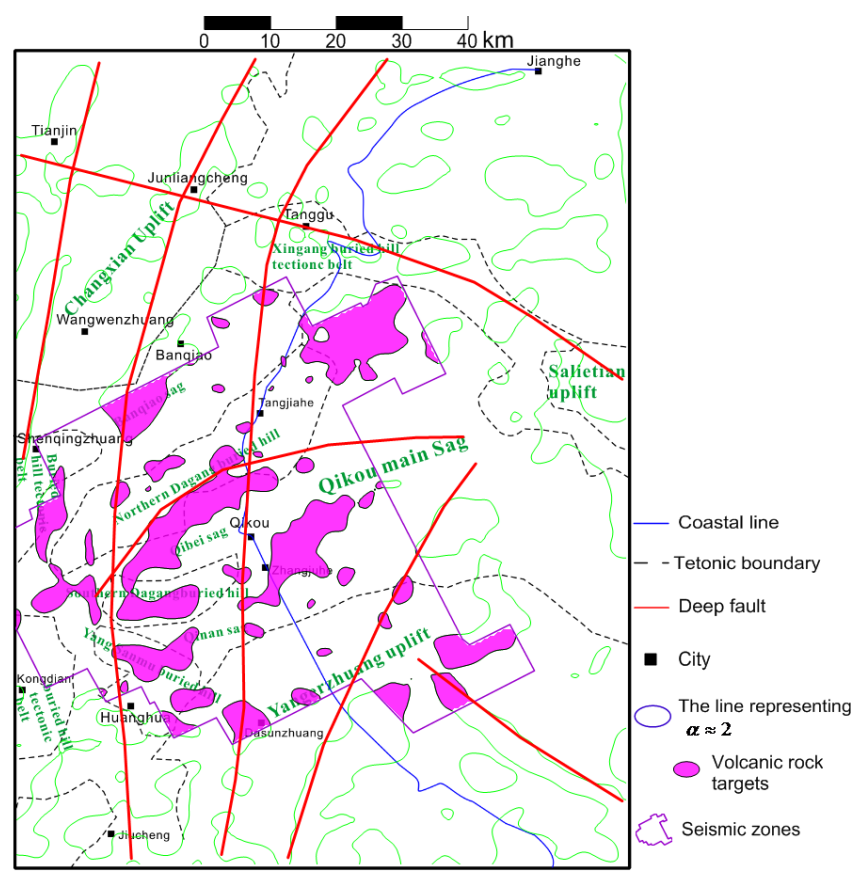

Fig. 13. Potential volcanic rock targets identified from RTP aeromagnetic singularities in the 3-D seismic work area of the Qikou depression.

In our case study, the magnetic anomalies of the volcanic rocks in the Qikou depression area were very weak owing to their large burial depth and the strong background field. In such a complex region, the weak anomalies associated with the locations of wells drilled through volcanic rocks are better recognised using the singularity mapping technique than by applying multiscale wavelet analysis. Both the deepseated faults and volcanic rock targets delineated by the sin- gularity indices in the 3-D seismic work area of the Qikou depression should be the subject of future investigation owing to their potential for acting as oil and gas reservoirs.

Acknowledgements. The authors would like to thank F. P. Agterberg, J. Wanliss, R. Zuo, Z. Chen and an anonymous reviewer for their critical reviews and constructive comments. This research was jointly supported by NSERC Discovery Research "Research and development of multifractal methods and GIS technology for mineral exploration and environmental assessments" (ERC-OGP 0183993) and a research project on "New methods for mineral resource potential assessment" (1212010733811). The Dagang oilfield Company of China National Petroleum Crop is grateful acknowledged for supplying the geophysical data.

Edited by: J. Wanliss

Reviewed by: F. Agterberg and one anonymous referee

\section{References}

Agterberg, F. P.: Multifractals and geostatistics, J. Geochem. Explor., 122, 113-122, doi:10.1016/j.gexplo.2012.04.001, 2012.

Benzi, R., Paladin, G., Parisi, G., and Vulpiani, A.: On the multifractal nature of fully developed turbulence and chaotic systems, J. Phys. A-Math. Gen., 17, 3521, doi:10.1088/03054470/17/18/021, 1984.

Chen, J. G., Xiao, F., and Chang, T.: Gravity and magnetic anomaly separation based on bidimensional empirical mode decomposition, Earth Science - Journal of China University of Geoscience, 36, 327-335, 2011.

Chen, Z., Cheng, Q., Chen, J., and Xie, S.: A novel iterative approach for mapping local singularities from geochemical data Nonlin. Processes Geophys., 14, 317-324, doi:10.5194/npg-14317-2007, 2007.

Cheng, Q. M.: Fractal/multifractal modeling and spatial analysis, keynote lecture, in: Progress of the International Mathematical 
Geology Association Conference, edited by: Pawlowsky-Glahn, V., Barcelona, Spain, 22-27 September, 1, 57-72, 1997.

Cheng, Q. M.: Spatial self-similarity and geophysical and geochemical anomaly decomposition, Progress in Geophysics, 16, 8-17, 2001.

Cheng, Q. M.: Singularity-generalized self-similarity-fractal spectrum (3S) models, Earth Science - Journal of China University of Geoscience, 31, 337-348, 2006.

Cheng, Q. M.: Mapping singularities with stream sediment geochemical data for prediction of undiscovered mineral deposits in Gejiu, Yunnan Province, China, Ore Geol. Rev., 32, 314-324, doi:10.1016/j.oregeorev.2006.10.002, 2007.

Cheng, Q. M.: Non-linear theory and power-law models for information integration and mineral resources quantitative assessments, Math. Geosci., 40, 503-532, doi:10.1007/s11004-0089172-6, 2008.

Cheng, Q. M.: Singularity modeling of geo-anomalies and recognition of anomalies caused by buried sources, Earth Science Journal of China University of Geoscience, 36, 307-316 2010.

Cheng, Q. M.: Singularity theory and methods for mapping geochemical anomalies caused by buried sources and for predicting undiscovered mineral deposits in covered areas, J. Geochem. Explor., 122, 55-70, doi:10.1016/j.gexplo.2012.07.007, 2012.

Cheng, Q. M. and Agterberg, F. P.: Singularity analysis of oremineral and toxic trace elements in stream sediments, Comput. Geosci., 35, 234-244, doi:10.1016/j.cageo.2008.02.034, 2009.

Cheng, Q. M. and Li, Q.: A fractal concentration-area method for assigning a color palette for image representation, Comput. Geosci., 28, 567-575, doi:10.1016/S0098-3004(01)000607, 2002.

Cheng, Q. M. and Zhao, P. D.: Singularity theories and methods for characterizing mineralization processes and mapping geoanomalies for mineral deposit prediction, Geoscience Frontiers, 2, 67-79, doi:10.1016/j.gsf.2010.12.003, 2011.

Dimitriu, P., Scordilis, E., and Karacostas, V.: Multifractal analysis of the Arnea, Greece seismicity with potential implications for earthquake prediction, in: Natural Hazards, edited by: Papadopoulos, G. A., Murty , T., Venkatesh, S., and Blong, R., Springer, 277-295, 2000.

Godano, C., Alonzo, M., and Bottari, A.: Multifractal analysis of the spatial distribution of earthquakes in southern Italy, Geophys. J. Int., 125, 901-911, doi:10.1111/j.1365-246X.1996.tb06033.x, 1996.

Hirabayashi, T., Ito, K., and Yoshii, T.: Multifractal analysis of earthquakes, Pure Appl. Geophys., 138, 591-610, doi:10.1007/BF00876340, 1992.

Hirata, T. and Imoto, M.: Multifractal analysis of spatial distribution of microearthquakes in the Kanto region, Geophys. J. Int., 107, 155-162, doi:10.1111/j.1365-246X.1991.tb01163.x, 1991.

Huang, C. Y., Wang, H., Wu, Y. P., Wang, J. H., Chen, S., Ren, P. G., Liao, Y. T., Zhao, X., and Xia, C. Y.: Genetic types and sequence stratigraphy models of Palaeogene slope break belts in Qikou Sag, Huanghua Depression, Bohai Bay Basin, Eastern China, Sediment. Geol., 261-262, 65-75, doi:10.1016/j.sedgeo.2012.03.005, 2012.

Lang, J.: Research on exploration and estimation technologies for subtle reservoir in slope of Qikou Sag, Ph.D. thesis, China university of Geoscience, 2008.
Lovejoy, S., Pecknold, S., and Schertzer, D.: Stratified multifractal magnetization and surface geomagnetic fields, I. Spectral analysis and modeling, Geophys. J. Int., 145, 112-126, doi:10.1111/j.1365-246X.2001.00344.x, 2001.

Lovejoy, S., Gaonac'h, H., and Schertzer, D.: Anisotropic Scaling models of rock density and the earth's surface gravity field, Math. Geosci., 40, 533-573, doi:10.1007/s11004-008-9171-7, 2008.

Mandelbrot, B. B.: How long is the coast of Britain? Statistical self-similarity and fractional dimension, Science, 156, 636-638, doi:10.1126/science.156.3775.636, 1967.

Mandelbrot, B. B.: Possible refinement of the lognormal hypothesis concerning the distribution of energy dissipation in intermittent turbulence. Statistical models and turbulence, Lect. Notes Phys., 12, 333-351, doi:10.1007/3-540-05716-1_20, 1972.

Mickus, K. L. and Durrani, B.: Gravity and magnetic study of the crustal structure of the San Francisco volcanic field, Arizona, USA, Tectonophysics, 267, 73-90, doi:10.1016/S00401951(96)00087-X, 1996.

Mostafa, M. E.: Finite cube elements method for calculating gravity anomaly and structural index of solid and fractal bodies with defined boundaries, Geophys. J. Int., 177, 887-902, doi:10.1111/j.1365-246X.2007.03660.x, 2008.

Mostafa, M. E.: Modeling magnetic anomalies of solid and fractal bodies with defined boundaries using the finite cube elements method, Geophysical Journal International, 177, 62-70, doi:10.1111/j.1365-246X.2008.04071.x, 2009.

Schertzer, D. and Lovejoy, S.: Physical modeling and analysis of rain and clouds by anisotropic scaling multiplicative processes, $\mathrm{J}$. Geophys. Res., 92, 9693-9714, doi:10.1029/JD092iD08p09693, 1987.

Thompson, D. T.: EULDPH: A new technique for making computer assisted depth estimates from magnetic data, Geophysics, 47, 31-37, doi:10.1190/1.1441278, 1982.

Turcotte, D. L.: Fractal and chaos in geology and geophysics, Cambridge University Press, England, 211 pp., 1992.

Wang, W., Zhao, J., and Cheng, Q.: Application of singularity index mapping technique to gravity/magnetic data analysis in southeastern Yunnan mineral district, China, J. Appl. Geophys., 92, 39-49, doi:10.1016/j.jappgeo.2013.02.012, 2013.

Wang, W. L., Zhao, J., and Cheng, Q. M.: Analysis and integration of geo-information to identify granitic intrusion as exploration targets in southeastern Yunnan District, China, Comput. Geosci., 37, 1946-1957, doi:10.1016/j.cageo.2011.06.023, 2012.

Wu, X. Y., Liu, T. Y., and Su, J. Q.: Gravity and magnetic anomaly characteristics and oil \& gas geological significance in middle and north part of the Huanghua Depression, Oil Geophys. Prospect., 45, 140-145, 2010.

Xie, S. Y., Cheng, Q. M., Chen, G., Chen, Z. J., and Bao, Z. Y.: Application of local singularity in prospecting potential oil/gas Targets, Nonlin. Processes Geophys., 14, 285-292, doi:10.5194/npg-14-285-2007, 2007.

Xu, Y., Hao, T. Y., Zhao, B. M., Zhou, L. H., Zhang, L. L., Li, Z. W., and Huang, S.: Investigation of igneous rocks in Huanghua Depression, North China, from magnetic derivative methods, J. Geophys. Eng., 8, 74-82, doi:10.1088/1742-2132/8/1/009, 2011.

Yang, H., Zhang, Y., Zou, C. N., Wen, B. H., and Li, M.: Volcanic rock distribution and gas abundance regularity in Xujiaweizi faulted depression, Songliao basin, Chinese Journal of Geophysics, 49, 1136-1143, 2006. 
Yang, Y. S., Li, Y. Y., and Liu, T. Y.: Continuous wavelet transform, theoretical aspects and application to aeromagnetic data at the Huanghua Depression, Dagang Oilfield, China, Geophys. Prospect., 58, 669-684, doi:10.1111/j.1365-2478.2009.00847.x, 2010.

Yang, Y. S., Li, Y. Y., and Liu, T. Y.: Gravity and magnetic investigation on the distribution of volcanic rocks in the Qinggelidi area, north-eastern Junggar Basin (north-west China), Geophys. Prospect., 60, 539-554, doi:10.1111/j.1365-2478.2011.01013.x, 2012.

Zhang, Z. S. and Wu, B. H.: Research status of igneous oil and gas reservoir and exploration technique at home and aboard, Natural Gas Exploration \& Development, 16, 1-26, 1994.

Zhao, P. D.: Geological anomaly theory and mineral deposits prediction: Advanced mineral resources assessment theory and methods, Geological Publishing House, Beijing, China, 1988.
Zhou, L. H., Fu, L. X., Lou, D., Lu, Y., Feng, J. Y., Zhou, S. H., Santosh, M., and Li, S. Z.: Structural anatomy and dynamics of evolution of the Qikou Sag, Bohai Bay Basin: Implications for the destruction of North China craton, J. Asian Earth Sci., 47, 94-106, doi:10.1016/j.jseaes.2011.06.004, 2012.

Zuo, R. and Cheng, Q.: Mapping singularities - a technique to identify potential $\mathrm{Cu}$ mineral deposits using sediment geochemical data, an example for Tibet, west China, Mineral. Mag., 72, 531534, doi:10.1180/minmag.2008.072.1.531, 2008.

Zuo, R., Xia, Q., and Zhang, D.: A comparison study of the CA and SA models with singularity analysis to identify geochemical anomalies in covered areas, Appl. Geochem., 33, 165-172, doi:10.1016/j.apgeochem.2013.02.009, 2013.

Zuo, R. G., Cheng, Q. M., Agterberg, F. B., and Xia, Q. L.: Application of singularity mapping technique to identify local anomalies using stream sediment geochemical data, a case study from Gangdese, Tibet, western China, J. Geochem. Explor., 101, 21 29, doi:10.1016/j.gexplo.2008.08.003, 2009. 